Disponível em

http://www.anpad.org.br/rac

RAC, Rio de Janeiro, v. 19, n. 4, art. 1, pp. 419-439, Jul./Ago. 2015

http://dx.doi.org/10.1590/1982-7849rac20151296

$((c))$ EY-NG

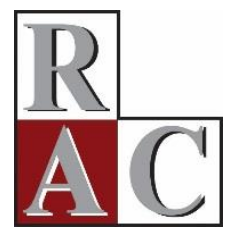

\title{
Ser seu Próprio Patrão? Aperfeiçoando-se a Educação Superior em Empreendedorismo
}

\section{Interested in Being a Business Owner? Improving Higher Education in Entrepreneurship}

Edmilson Lima

Universidade Nove de Julho - UNINOVE

Rose Mary Almeida Lopes Escola Superior de Propaganda e Marketing - ESPM

Vânia Maria Jorge Nassif Universidade Nove de Julho - UNINOVE

Dirceu Silva

Universidade Nove de Julho - UNINOVE 


\title{
Resumo
}

O artigo tem por objetivo identificar formas de se melhorar a educação superior em empreendedorismo, focando o caso dos estudantes brasileiros interessados em ser seus próprios patrões, ou seja, em terem seus próprios negócios. Eles são aqui chamados de fundadores intencionais. O estudo é um survey complementado por uma breve revisão da literatura. O questionário online foi respondido por 12.604 fundadores intencionais de um amplo espectro de cursos superiores de 37 instituições de ensino superior públicas e privadas brasileiras. Segundo suas respostas, eles têm mais alta demanda por educação em empreendedorismo e mais alta intenção empreendedora do que se vê em outros países. Três hipóteses foram testadas. Os resultados mostram que sua intenção de empreender e seu nível de crença em serem competentes para empreender com sucesso (self-efficacy ou autoeficácia, em Português) são indiferentes à variação do quanto fazem de disciplinas e atividades de educação em empreendedorismo (EE) no ensino superior. Por outro lado, há relação significante e positiva entre a intenção empreendedora e a demanda por EE. A elevada demanda dos estudantes parece poder ser aproveitada como facilitadora do necessário aperfeiçoamento da EE no Brasil. As discussões e as conclusões do fim do artigo oferecem recomendações não apenas para a melhoria da educação superior, mas também para a realização de mais pesquisas.

Palavras-chave: educação; empreendedorismo; intenção empreendedora; estudantes; fundadores intencionais.

\begin{abstract}
The objective of this paper is to identify ways of improving higher education in entrepreneurship, focusing on Brazilian students who want to be self-employed or have their own business. In this article, they are named intentional founders. The study is a survey complemented by a short literature review. The online questionnaire was answered by 12,604 Brazilian students from 37 public and private higher-education institutions. According to their answers, they present a higher demand for entrepreneurship education and a higher entrepreneurial intention than students from other countries. Three hypotheses were tested. Results show that more or less entrepreneurship education (EE) has no effect on students' entrepreneurial intention and self-efficacy (self-perception of being wellprepared to do successful entrepreneurial activities). On the other hand, entrepreneurial intention has a significant and positive association with demand for EE. Taking advantage of students' high demand seems attractive to facilitate the necessary improvement of EE in Brazil. The discussions and conclusions at the end of the paper offer recommendations not only for the improvement of higher education, but also for conducting further research.
\end{abstract}

Key words: education; entrepreneurship; entrepreneurial intention; students; intentional founders. 


\section{Introdução}

Se querem ter potencial empreendedor, ou seja, ter capacidade inovadora, apresentarem resiliência, renovarem-se e desenvolverem-se, os países precisam de empreendedores potenciais (Krueger \& Brazeal, 1994; Shapero, 1981). São pessoas que obtêm a preparação necessária para serem seus próprios patrões, tendo um negócio ou mesmo para empreender como empregados em uma organização já existente. À frente de iniciativas de negócio, poderão oferecer mais postos de trabalho, explorar necessidades de mercado ainda não atendidas e gerar inovações. Aqueles que não tiverem os requisitos necessários para empreender não estarão em condições de desempenhar tal papel. Afinal, a preparação é uma condição necessária para serem identificadas e serem exploradas oportunidades que tornem viáveis os acontecimentos empreendedores (Reynolds, 1991; Shapero \& Sokol, 1982).

Como se poderia deduzir, ser um empreendedor potencial não implica necessariamente também ter intenção de empreender ou vice-versa. Em outras palavras, há aqueles que têm a preparação para empreender e não têm intenção de fazê-lo, assim como aqueles que querem fazê-lo e não estão preparados para tanto. Quando se trata dos fatores dependentes do próprio indivíduo, a junção do potencial com a intenção é, contudo, uma grande propulsora e uma importante viabilizadora do empreendedorismo.

Para os países em geral, em especial os emergentes, como o Brasil, tal junção é um importante fornecedor de novos empreendedores. Mostra-se particularmente promissora quando se pensa nas pessoas que querem ser seus próprios patrões tendo uma empresa - aqui chamados de fundadores intencionais - e são estudantes universitários. Uma razão importante para tanto é que tal intenção normalmente os impulsiona a buscar a preparação para empreender (Fayolle, Gailly, \& Lassas-Clerc, 2006), a qual reforça a díade intenção-potencial, dando-lhes melhores condições de realizar sua intenção. Percebendo-se mais bem preparados para empreender e podendo contar com um entorno que valoriza e apoia o empreendedorismo, tendem a avaliar a iniciativa empreendedora vislumbrada como factível e desejável. Tal díade ganha então ainda mais força e aumenta a intenção e a tendência à realização da intenção (Krueger \& Brazeal, 1994; Shapero \& Sokol, 1982).

Como se sabe, os jovens são, em boa medida, definidores do futuro de um país. Quando são estudantes universitários em uma economia emergente em que uma pequena parcela da população faz estudos superiores, como ocorre no Brasil, a preparação oferecida pela educação superior pode aumentar seu potencial de impacto no futuro do país em relação à maior parte da população. Nesse sentido, poderse-ia argumentar que, desses estudantes, aqueles que têm intenção empreendedora estariam entre os mais propensos a dar contribuições significativas para a sociedade, dada a relevância socioeconômica da carreira que os atrai - quanto à geração de empregos e à geração de inovações, por exemplo (Lanero, Vázquez, Gutiérrez, \& García, 2011). Portanto, parece importante que se assegure a qualidade da educação em empreendedorismo (EE) nas universidades brasileiras, pensando-se particularmente nos estudantes que são fundadores intencionais.

Não apenas em relação aos fundadores intencionais, mas também de modo geral, o interesse pela EE cresceu significativamente ao longo da última década. Vários fatores contaram para isso. Dentre eles, há o argumento amplamente aceito de que ela contribui no desenvolvimento da inovação nas organizações em geral e na promoção do empreendedorismo que se manifesta, entre outras coisas, pela criação de novas empresas e novos postos de trabalho (Guerra \& Grazziotin, 2010; Lanero et al., 2011). A importância da EE para o desenvolvimento dos países já foi reconhecida nos mais elevados níveis de discussão da Conferência sobre Comércio e Desenvolvimento das Nações Unidas (United Nations Conference on Trade and Development [UNCTAD], 2011).

Mesmo que não queiram ter ou não venham a ter seu próprio negócio, os estudantes podem ser beneficiados em sua formação com o desenvolvimento, mesmo que moderado, de conhecimentos, atenção e/ou habilidades propícias ao empreendedorismo. A premissa de que a EE não é apenas geradora de aprendizagem para se empreender, mas, sobretudo, para o pensamento criativo, a geração de inovações e o crescimento do senso de autoestima e de responsabilidade (Heinonen, Kovalainen, \& 
Pukkinen, 2006) faz com que seja vista como ainda mais necessária nas instituições de ensino superior (IES) em variados estudos acadêmicos.

Assim, mostra-se promissora a busca de formas de aperfeiçoamento da EE no ensino superior, particularmente no contexto brasileiro, em que são raros e necessários os estudos úteis a tal intento. Sem isso, perdura o risco de que ela seja pouco (ou contra-) producente, podendo priorizar caminhos de formação pouco coerentes com o contexto, a capacidade e os interesses do país, das IES, dos professores e dos estudantes (Lima, Lopes, Nassif, \& Silva, no prelo). Como visto, essa é uma preocupação particularmente relevante quanto aos estudantes brasileiros que são fundadores intencionais. Portanto, esse artigo tem por objetivo identificar formas de se melhorar a educação superior brasileira em empreendedorismo com atenção particular na realidade deles. Por isso, focamos aqui as intenções empreendedoras e a demanda por EE em uma amostra de 12.604 universitários que são fundadores intencionais.

\section{Fundamentação Teórica}

$\mathrm{Na}$ busca de entendimento dos antecedentes da escolha de carreira dos estudantes em empreendedorismo, tem sido amplamente empregada a teoria do comportamento planejado (TCP), desenvolvida por Ajzen (1991, 2002) e Fishbein e Ajzen (1975). Muitos estudos confirmam sua utilidade e fundamentam sua utilização (Fayolle et al., 2006; Liñán \& Chen, 2009; Miller, Bell, Palmer, Gonzalez, \& Petroleum, 2009; Souitaris, Zerbinati, \& Al-Laham, 2007, entre outros).

Embora sofra críticas por não assegurar que um possível empreendedor vá efetivamente empreender, a TCP contribui para se entender a formação da intenção empreendedora (Fayolle et al., 2006; Liñán \& Chen, 2009; Miller et al., 2009; Souitaris et al., 2007). Em outras palavras, auxilia na compreensão de um tema central da pesquisa aqui apresentada, cuja análise, associada à da demanda dos estudantes, tem o potencial de sugerir caminhos para o aperfeiçoamento da educação em empreendedorismo.

Visando ao aproveitamento desse potencial, a TCP foi adotada em nossa pesquisa. Um benefício adicional é que essa adoção favorece a compatibilidade e a possibilidade de comparação dos dados e resultados da pesquisa com os do estudo internacional GUESSS, baseado no mesmo modelo teórico. Explorando tal benefício, expomos alguns resultados do estudo internacional neste artigo a título de comparativos para melhor compreensão dos dados brasileiros. Contudo, antes disso, sintetizamos na presente seção as bases conceituais da pesquisa.

Segundo Ajzen (1991), a intenção resulta da atitude de um indivíduo quanto à realização de um dado comportamento, de normas subjetivas e do controle comportamental percebido pelo indivíduo. No caso específico de um estudo em empreendedorismo, o conceito refere-se à atratividade da ideia de empreender. As normas subjetivas consistem na percepção da pressão social favorável ou não, exercida por pessoas importantes ou de referência no círculo de relações do indivíduo, para que ele leve adiante ou não a ideia de empreender. Tais normas são alimentadas pelas chamadas influências normativas, ou seja, influências sociais que conduzem a certo comportamento, como são as expectativas da família do possível empreendedor. Já o conceito de controle comportamental percebido é relativo à percepção de dificuldade ou facilidade para se desenvolver o comportamento empreendedor levando-se em conta experiências passadas, deficiências e obstáculos. Concerne, portanto, não só à autoeficácia em empreendedorismo, mas também ao grau de controle do próprio indivíduo sobre seu comportamento (locus de controle, segundo Ajzen, 2002 e Brockhaus, 1980).

A força da intenção é maior à medida que a atitude, as normas subjetivas e o controle comportamental percebido são favoráveis ao comportamento considerado, o que torna o indivíduo mais inclinado a realizá-lo (Ajzen, 1991). No entanto, a realização efetiva da intenção depende não apenas de sua motivação pessoal, mas também de fatores não motivacionais, como os recursos, as oportunidades 
e a condição financeira (Ajzen, 1991). Fatores motivacionais e não motivacionais influenciam o nível de controle do indivíduo sobre seu comportamento, ou seja, seu locus de controle (Ajzen, 1991, 2002).

Como lembrado por Krueger e Brazeal (1994) e Tran (2011), a TCP apresenta sobreposições em relação ao modelo do acontecimento empreendedor de Shapero e Sokol (1982), o que ajuda a compreender os propósitos da TCP em sua aplicação nos estudos do empreendedorismo. Shapero e Sokol (1982) veem o empreendedorismo como uma escolha profissional e entendem que a decisão de se criar uma empresa é iniciada, entre outros, por fatores contextuais que desestabilizam a linha dos acontecimentos na vida do possível empreendedor. Mas tal decisão deve ser percebida por este último como desejável e factível. Assim, a percepção do nível de desejo pode ser entendida como próxima do conceito de atitude (elemento pessoal) e de norma social (elemento social) da TCP, enquanto a factibilidade tem afinidade com o conceito de controle comportamental percebido (Tran, 2011). Segundo a TCP e o modelo de acontecimento empreendedor, para que a intenção empreendedora se desenvolva com intensidade na esfera da subjetividade de um estudante, o empreendedorismo deve lhe parecer uma carreira desejável e factível (Tran, 2011).

\section{Demandas por melhorias na EE em diferentes países}

Quando se trata das necessidades de melhoria da EE, são mais frequentes pesquisas em que especialistas ou professores sejam as fontes de dados consultadas. São poucos os estudos baseados na perspectiva dos estudantes. Os parágrafos a seguir resumem alguns deles.

Gasse, Camion, Ghamgui e Tremblay (2006) compararam avaliações da EE feitas por um conjunto de 656 estudantes de Administração e Engenharia da Tunísia, da França e da província do Quebec (Canadá). De 76\% a 88\% dos estudantes dos diferentes países consideraram as atividades práticas e participativas muito úteis na preparação para empreender. De $40 \%$ a $52 \%$ deles julgaram o ambiente favorável à inovação nas IES e nas empresas como um fator muito importante. Também recebeu destaque a oferta de apoio às atividades empreendedoras. Por exemplo, um terço dos alunos tunisianos viu sua falta como um obstáculo real ao florescimento do empreendedorismo. Segundo a perspectiva dos estudantes dos três países, as IES em que se quer incentivar o empreendedorismo podem ser mais efetivas se fomentarem um ambiente favorável à inovação, oferecerem apoio a iniciativas empreendedoras e focarem a EE em atividades práticas.

Em estudo posterior, Gasse e Tremblay (2011) comparam respostas de um total de 2.053 estudantes, também dos cursos de Administração e de Engenharia, mas de sete países. Sobre a contribuição das atividades de ensino para o estímulo ao empreendedorismo, as sete amostras sinalizaram (79\% a 95\% dos alunos) que são úteis em projetos e iniciativas práticas, simulações, estágios e experiências de trabalho. Quanto à contribuição das disciplinas de empreendedorismo, as porcentagens declinaram claramente para 20 a 40\%, com exceção dos estudantes colombianos, com 82\%.

Com uma amostra de 168 estudantes de uma universidade finlandesa, Drost (2010) identificou um relevante papel da autoeficácia como mediadora dos resultados da EE. Segundo a percepção dos alunos, a aprendizagem de competências básicas para se empreender (identificação de oportunidades de novos negócios, avaliação das oportunidades, iniciação de um negócio e empreendedorismo organizacional) afeta positivamente sua autoeficácia. Assim sendo, Drost (2010) argumenta a favor de uma EE focada na prática. Para ele, esse tipo de EE deveria incluir, por exemplo, a interação com empreendedores tomados como modelo e atividades estimulantes da autoconfiança.

Os resultados dos três estudos reforçam a literatura predominante, segundo a qual, na perspectiva de especialistas, os sistemas de apoio a iniciativas empreendedoras e a abordagem prática de ensino são recomendáveis para se gerar qualidade na EE. Essas recomendações e o reforço dado a elas pelos três estudos já são potenciais contribuições para se cumprir com o objetivo do presente artigo. Podem, contudo, confimar-se e ganhar mais consistência para o contexto brasileiro à luz do conteúdo da próxima seção e, principalmente, dos resultados da nossa pesquisa empírica aqui detalhada. 


\section{Necessidades de melhoria da EE segundo estudos brasileiros}

O estudo do GEM, intitulado Empreendedorismo no Brasil: 2008 (Greco et al., 2009), desenvolveu um tópico específico sobre educação e treinamento, e apresenta características de uma realidade que destoam do que seus autores consideram recomendável. Informa, com base em levantamentos estatísticos do Instituto Nacional de Estudos e Pesquisas Educacionais (INEP/MEC), que existiam 39.555 cursos superiores no Brasil em 2008, dos quais 3.465 programas de ensino eram da área de Administração, e 988 das áreas de Engenharia da Computação, Informática e Sistemas de Informação. Essas quatro áreas são normalmente precursoras na oferta de disciplinas de empreendedorismo. Mas registravam-se apenas 25 programas de ensino com conteúdos específicos de empreendedorismo e gestão de pequenos negócios ( $88 \%$ sendo presenciais). Os programas estavam concentrados nas regiões sudeste e sul do país, as mais desenvolvidas. Segundo os autores, com esses números, a oferta de disciplinas e atividades de empreendedorismo nas IES é muito modesta e está associada à carência de professores capacitados.

Além disso, os resultados de Greco et al. (2009) apontaram que, entre os empreendedores que dão início a sua própria empresa, $90 \%$ nunca fizeram qualquer disciplina ou atividade de treinamento relativo à abertura de negócios, em qualquer nível de ensino. $40 \%$ dos empreendedores que participaram de alguma atividade de EE (apenas $4 \%$ do total de empreendedores) puderam fazê-lo em disciplinas majoritariamente optativas de formação universitária.

Uma pesquisa nacional realizada pelo Conselho Federal de Administração (CFA) (Andrade et al., 2006) consultou uma amostra de 10.552 egressos dos cursos de Administração, além de professores e empresas. Sugeriu novos conteúdos para que as IES formem melhor seus alunos e lhes ofereçam formação mais adequada à realidade do mercado. Os principais conteúdos foram: desenvolvimento do empreendedorismo (apontado por 46,03\% dos respondentes), gestão de micro e pequenas empresas (segundo $27,34 \%$ das respostas), gestão ambiental e desenvolvimento sustentável $(23,51 \%$ das respostas), e ética empresarial (20,11\% das respostas).

Mais recentemente, outra pesquisa do CFA (Mello, Melo, \& Mattar, 2011) abordou 17.982 egressos de Administração. Dessa vez, as quatro principais necessidades de melhoria desse curso superior apontadas por eles foram desenvolvimento do empreendedorismo (34,51\% das respostas), gestão ambiental e desenvolvimento sustentável (25,61\%), criatividade e inovação (20,65\%) e gestão de micro e pequena empresa (20,29\%). Portanto, com as duas pesquisas do CFA, identificou-se uma necessidade considerável de aperfeiçoamento da oferta de EE e de gestão de pequenos negócios para o curso de Administração.

Em outro estudo, Anjos, Fechine e Nóbrega (2005) notaram que um quarto dos alunos de Administração da Universidade Federal de Campina Grande considerou bom ou ótimo o nível do tratamento do empreendedorismo em sua IES. Os autores avaliaram como reduzida essa proporção. O conjunto dos estudantes recomendou mudanças, principalmente em prol do enfoque prático na $\mathrm{EE}$, da interdisciplinaridade, da ampliação do tratamento do tema e da capacitação para os professores, apoiada em incentivos.

Em sua pesquisa Empreendedorismo das Universidades Brasileiras, Suedekum e Miller (2011) constatam que, comparativamente a outras universidades do mundo, as disciplinas oferecidas no Brasil ainda convidam pouco os empreendedores para falar aos estudantes e não se concentram em atividades práticas. Os autores alertam que os alunos que são fundadores intencionais deveriam ser mais envolvidos com a realidade vivida pelos empreendedores, de modo a terem referências precisas sobre os pontos que deveriam aperfeiçoar em si mesmos.

Deve-se também considerar que a EE no Brasil é limitada pelo fato de suas disciplinas se restringirem essencialmente ao desenvolvimento de um plano de negócios (Degen, 2009; Guerra \& Grazziotin, 2010). À luz dessa realidade, pode-se dizer que a maioria dos estudantes brasileiros carece de diversificação, para além do plano de negócios, no conjunto das disciplinas e atividades de EE. 
O quadro esboçado até aqui sugere que há muito a ser feito para se aperfeiçoar a EE no Brasil, o que é corroborado pelos estudos mais recentes de Lima, Lopes, Nassif e Silva (no prelo) e Lima, Hashimoto, Melhado e Rocha (2014). De modo geral, os dois convergem com os resultados e recomendações dos demais estudos brasileiros aqui citados. Consultando a literatura e uma amostra de 25.751 universitários, o primeiro deles identificou cinco grandes desafios da EE no país: aumentar a oferta de cursos, disciplinas e atividades de EE; treinar mais professores; promover proximidade e contato com os empreendedores e sua realidade; dar foco à prática; diversificar a oferta de EE para além do plano de negócios. Os resultados de Lima et al. (no prelo) também mostram uma relação estatística negativa da EE com a intenção empreendedora e a autoeficácia em empreendedorismo dos estudantes. O mesmo ocorreu entre a intenção empreendedora e a demanda por EE. Assim, os estudantes que mais aproveitaram as ofertas de EE nas universidades apresentaram menor intenção empreendedora e menor autoeficácia. Os estudantes com mais intenção empreendedora, inclusive fundadores ativos, mostraram menor demanda por EE. Com tais resultados, ganha mais relevância o questionamento do que se faz e da qualidade do trabalho na EE universitária brasileira, assim como a necessidade de atenção à superação dos cinco desafios. Para tanto, contudo, podem contribuir na geração de progressos as oportunidades identificadas pelos autores, como a atitude positiva e a alta demanda dos estudantes quanto à EE.

De modo complementar, pesquisa qualitativa de Lima et al. (2014) baseou-se em entrevistas semiestruturadas com 22 professores de diferentes partes do Brasil e em seis grupos de foco que totalizaram 60 alunos - 63,3\% fundadores intencionais e 23,3\% fundadores ativos. Os estudantes demonstraram ter grande demanda, entre outras coisas, por disciplinas mais práticas e próximas da realidade dos empreendedores. Quanto aos professores, os autores desenvolveram uma tipologia que os classifica em cinco tipos, segundo a dimensão do projeto de EE que realizam, seu perfil, suas motivações de trabalho e suas práticas de EE. Dentre eles, os professores de perfil visionário-realizador apresentamse como os de maior impacto na EE, dada a dimensão do seu projeto e seu trabalho voltado principalmente ao estabelecimento de uma cultura em prol do empreendedorismo na IES em que atuam. No outro extremo da tipologia, vê-se o professor de perfil executor, motivado essencialmente para ser remunerado e cumprir com as exigências de seu cargo, não tendo interesse prévio relevante para lecionar em EE. Segundo os autores, este tende a ser um tipo muito comum nas IES brasileiras, dada a grande demanda de professores de EE e a falta de treinamento de um número adequado deles para atendê-la. A tipologia mostra-se útil face à acentuada carência de aprofundamento teórico e de tipologias para o avanço do estudo da EE descrita por Byrne, Fayolle e Toutain (2014).

\section{Hipóteses}

As características pessoais (Alvarez \& Busenitz, 2001) e as habilidades (Galloway, Anderson, Brown, \& Wilson, 2005) para empreender podem ser desenvolvidas ou fortalecidas com a educação. Se as universidades promoverem a EE e se empenharem em desenvolver o potencial empreendedor (Vyakarnam, 2005) em combinação com diferentes competências (Gibb, 2009; Kirby, 2005) dos estudantes, podem promover o desenvolvimento de consciência e interesse propícios ao empreendedorismo e à exploração de formas alternativas de trabalho (Galloway et al., 2005).

Há também evidências de que experiências empreendedoras propiciadas pela $\mathrm{EE}$ aos alunos despertam ou fortalecem sua intenção empreendedora (Peterman \& Kennedy, 2003). Adicionalmente, se as IES não oferecerem EE (ou adequada EE), deve-se esperar que os estudantes estejam menos propensos a empreender (Alvarez \& Busenitz, 2001).

Considerando-se essa linha de raciocínio predominante na literatura e que sustenta o efeito estatisticamente positivo da EE sobre a intenção de empreender dos estudantes universitários (Alvarez \& Busenitz, 2001; Franke \& Luthje, 2004; Kourilsky \& Walstad, 1998; Peterman \& Kennedy, 2003), configura-se a seguinte hipótese a ser testada: 
Hipótese 1: Fazer disciplinas e atividades de EE no ensino superior aumenta a intenção empreendedora dos estudantes universitários que são fundadores intencionais.

Também ajuda a sustentar essa primeira hipótese a concepção introduzida no início deste artigo segundo a qual os diferentes processos que reforçam a díade intenção-potencial elevam progressivamente a intenção empreendedora. Com o auxílio do modelo de potencial empreendedor (Krueger \& Brazeal, 1994), nota-se que a intensificação de fatores, como a autoeficácia em empreendedorismo, provocada pela EE ou outras atividades de preparação (Wilson, Kickul, \& Marlino, 2007), eleva a intenção empreendedora. O conceito de autoeficácia (self-efficacy) é definido como "a crença das pessoas em sua capacidade para produzirem os efeitos desejados por suas próprias ações" (Bandura, 1997, p. vii, tradução nossa). Já a autoeficácia em empreendedorismo refere-se à percepção de si como alguém preparado para realizar atividades empreendedoras com sucesso (Chen, Greene, \& Crick, 1998).

Portanto, em outras palavras, quanto mais elevado é o nível de percepção de si mesmas como pessoas preparadas para empreender com sucesso, mais intenção empreendedora as pessoas tendem a ter (Chen et al., 1998). Ademais, como podem desenvolver progressivamente sua autoeficácia e seu potencial para empreender, além de apresentar níveis variáveis de desejo de empreender, os fundadores intencionais normalmente apresentam (entre si e cada um em separado, ao longo do tempo) flutuações do nível de sua intenção empreendedora. $\mathrm{O}$ fato de serem fundadores intencionais não implica que já têm um nível elevado ao máximo e rigidamente estável de intenção empreendedora. Vê-se o reconhecimento desse fato, por exemplo, no Global University Entrepreneurial Spirit Student Survey (GUESSS - www.guesssurvey.org), realizado desde 2003 e organizado por pesquisadores da Universidade St. Gallen, Suíça. Ele utiliza na coleta e na análise de dados, para estudantes que são fundadores intencionais e outros, uma classificação crescente da intenção empreendedora (Sieger, Fueglistaller, \& Zellweger, 2011), algo que se repete em diferentes publicações feitas a partir do GUESSS (por exemplo: Laspita, Breugst, Heblich, \& Patzelt, 2012; Lima et al., no prelo; Zellweger, Sieger, \& Halter, 2011).

Os níveis de intenção empreendedora considerados no GUESSS referem-se às respostas obtidas na coleta de dados do estudo com o pedido feito aos respondentes para indicarem se têm pensado e o quão seriamente têm pensado em criar seu próprio negócio (Lima et al., no prelo; Sieger et al., 2011). Os níveis (respostas possíveis) são: (A) nunca; (B) apenas em linhas gerais; (C) repetidamente; (D) é algo relativamente concreto; (E) eu tomei a decisão explícita de fundar uma empresa; (F) eu tenho uma previsão consistente de datas para dar os diferentes passos da fundação; $(\mathrm{G})$ eu já comecei a realização da fundação; (H) eu já sou meu próprio patrão na empresa que eu fundei; (I) eu já fundei mais de uma empresa e estou atuando em pelo menos uma delas (Lima et al., no prelo; Sieger et al., 2011). Esses autores consideram como fundadores intencionais os respondentes que escolheram as opções de resposta $\mathrm{C}$ a $\mathrm{G}$, enquanto veem aqueles das opções $\mathrm{A}$ e B como não fundadores e os das respostas $\mathrm{H}$ e I como fundadores ativos.

Um dos pressupostos mais básicos e evidentes que sustentam a defesa da oferta de EE é que ela auxilia na preparação e no desenvolvimento de competências para empreender dos estudantes e no desenvolvimento de outros benefícios (como autoestima, criatividade e aspectos da geração de inovação) úteis também àqueles que não pensam em empreender (Alvarez \& Busenitz, 2001; Galloway et al., 2005; Heinonen et al., 2006). Isso inclui a noção de que fazer disciplinas e atividades de EE amplia a autoeficácia dos estudantes, como afirmam Wilson, Kickul e Marlino (2007) e Segal, Borgia e Schoenfeld (2005 como citado em Pihie, 2009).

Configura-se assim mais uma hipótese a testar:

Hipótese 2: Fazer disciplinas e atividades de EE no ensino superior aumenta a autoeficácia empreendedora dos estudantes universitários que são fundadores intencionais.

Em complementaridade aos testes das hipóteses 1 e 2, interessa-nos considerar os efeitos da intenção empreendedora sobre a demanda em relação à EE (por exemplo, demanda por melhorias da EE 
ou mais disciplinas de EE) advinda dos estudantes universitários, sem deixar de lado as contribuições de pesquisadores especialistas. Várias dessas contribuições são levantadas na seção anterior do artigo, que destaca a demanda estudantil segundo a literatura.

Como sugerem autores que citamos nas páginas precedentes, a EE tem impacto sobre a intenção empreendedora e vice-versa. Em um dos sentidos da relação entre os conceitos, nota-se que a intenção empreendedora é um importante determinante do interesse e das escolhas dos alunos quanto às disciplinas e atividades de formação. Por isso, ela é vista como um preditor do desenvolvimento de competências empreendedoras (Fayolle et al., 2006). Assim, a compreensão da intenção empreendedora dos estudantes e de sua percepção sobre disciplinas e atividades de EE é necessária para se formular recomendações de melhorias da EE (Lima et al., no prelo). Por esse motivo, realizamos também o teste da hipótese a seguir:

Hipótese 3: Uma maior intenção empreendedora aumenta a demanda por disciplinas e atividades de EE por parte de estudantes universitários que são fundadores intencionais.

\section{Métodos de Pesquisa}

A pesquisa aqui descrita é quantitativa, um survey. Os surveys são pesquisas em que a obtenção de dados pode ser feita por meio de amostragens ou de grupos com critérios de julgamento (Babbie, 1990). No caso da pesquisa em questão, realizada pela primeira vez no Brasil, optamos por fazer pedidos de resposta com o link do questionário online a estudantes de IES brasileiras. Os convites foram a eles encaminhados em e-mails por professores, coordenadores e/ou diretores de programas de ensino ou a eles disponibilizados em sites de internet ou na intranet dos estudantes. Os professores, coordenadores e diretores foram convidados a apoiar a coordenação nacional do Estudo GUESSS Brasil na coleta de dados por meio de contatos pessoais, por e-mail e por telefone.

O questionário usado é uma versão do instrumento de coleta de dados do estudo GUESSS internacional, traduzido e validado teoricamente para o Português por especialistas em empreendedorismo e EE no Brasil. Contém 16 grupos de questões de múltipla escolha e escalas de cinco ou sete pontos. Entre outros elementos, pede aos respondentes dados mensuráveis sobre EE, oferta de disciplinas e atividades de EE, bem como sobre o contexto universitário (Souitaris et al., 2007 - com adaptações). Acomoda dados também sobre a intenção empreendedora e seus determinantes, incluindo o locus de controle e a autoeficácia (Chen et al., 1998; Levenson, 1973; Liñán \& Chen, 2009), e também contém uma escala reduzida referente a motivos pessoais de escolha de carreira (Carter, Gartner, Shaver, \& Gatewood, 2003). Estudos anteriores, como os de Bergmann (2012), Laspita, Breugst, Heblich e Patzelt (2012), Lima et al. (no prelo), Nelson, Lima e Nassif (2014) e Zellweger, Sieger e Halter (2011), são exemplos de pesquisas empíricas e acadêmicas feitas a partir do GUESSS ${ }^{(1)}$.

O tratamento dos dados foi feito com análises de frequência das respostas, pois a amostra se configurou como infinita em termos estatísticos (Levy \& Lemesshow, 1999). Os procedimentos metodológicos também incluíram o teste paramétrico de hipótese ANOVA, pois a distribuição das variáveis independentes utilizadas pôde ser entendida como normal, segundo os resultados dos testes de Kolmogorov-Smirnov ( $\mathrm{p}>0,05$ ). Adicionalmente, testes de homogeneidade da variância (testes de Levene) para as mesmas variáveis independentes também se mostraram não significantes ( $p>0,05)$. Esses dois testes mostram que os pressupostos do teste ANOVA foram atendidos (Everitt, 2006). Tais variáveis foram preparadas com o uso da análise fatorial exploratória (AFE) com rotação VARIMAX de fator único para se aglutinar em valores únicos os dados obtidos com diferentes itens de escala do questionário e se calcular valores de regressão (Hair, Anderson, Tatham, \& Black, 2010). Explicando melhor, a técnica de AFE com fator único permite que se possa definir uma reta de regressão, a qual possibilita calcular os valores dos $\mathrm{Y}$ ajustados $(\mathrm{Y}=\mathrm{aX}+\mathrm{b})$ e, assim, obter-se um valor que classifica cada respondente segundo a totalidade das variáveis escolhidas para tal finalidade. O método de rotação foi VARIMAX, pois leva a uma disposição dos dados propícia à melhor diferenciação entre eles, o que facilita sua classificação (Hair et al., 2010). 
O survey foi realizado em 37 IES brasileiras dispersas geograficamente ${ }^{(2)}$ com 12.604 respondentes. Eles foram selecionados para o estudo por terem sido identificados como fundadores intencionais, segundo as respostas que deram variando das opções $\mathrm{C}$ a $\mathrm{G}$ (apresentadas na seção precedente deste artigo) quanto à indicação do quanto têm pensado e o quão seriamente têm pensado em criar seu próprio negócio. Preencheram o questionário de abril a junho de 2011 no Brasil. Tal número considera apenas respostas dadas ao longo de 15 minutos ou mais, pois os testes de resposta mostraram problemas de qualidade para respostas dadas em menos tempo. O GUESSS internacional é um panel study que envolveu 25 países em 2011, excetuando-se o Brasil, nos quais 25.922 respondentes informaram ser fundadores intencionais.

A amostra brasileira não foi obtida randomicamente, pois responderam o questionário os alunos que se interessaram pelo convite para fazê-lo. Contudo, o tamanho da amostra em questão $(n=12.604)$ e a dispersão geográfica dos respondentes favorecem a identificação de aspectos nacionalmente relevantes para a melhoria da EE no Brasil. O fato de a coleta e de o processamento dos dados terem seguido os padrões do GUESSS internacional foi útil, entre outras finalidades, à comparação entre dados brasileiros e estrangeiros. É também propício à comparação entre universidades tomadas à parte de um ou mais países, uma possibilidade em aberto para estudos futuros.

A seguir, apresentamos diferentes características da amostra brasileira usando dados do GUESSS internacional como apoio para melhor compreensão dos dados do Brasil ${ }^{(3)}$ :

Idade: $50,3 \%$ dos respondentes brasileiros estão na faixa abaixo de 25 anos; $27,2 \%$ na de 25 a 30 anos; e $22,5 \%$ na faixa acima de 30 anos. As porcentagens da amostra internacional são respectivamente $63,0 \%, 26,7 \%$ e $10,3 \%$.

- Gênero: o Brasil tem 51,3\% de homens na amostra e 48,7\% de mulheres; os respondentes estrangeiros são $53,2 \%$ de homens e $46,8 \%$ de mulheres.

Nível de estudo: 94,3\% dos estudantes brasileiros são graduandos, 1,0\% mestrandos, 3,6\% estudantes de MBA ou especialização, $0,5 \%$ de doutorado e $0,6 \%$ de pós-doutorado; para a amostra internacional, os porcentuais são $73,4 \%, 21,4 \%, 2,1 \%, 2,7 \%$ e $0,4 \%$ respectivamente.

O campo de estudo dos respondentes das duas amostras segue discriminado na Figura 1.

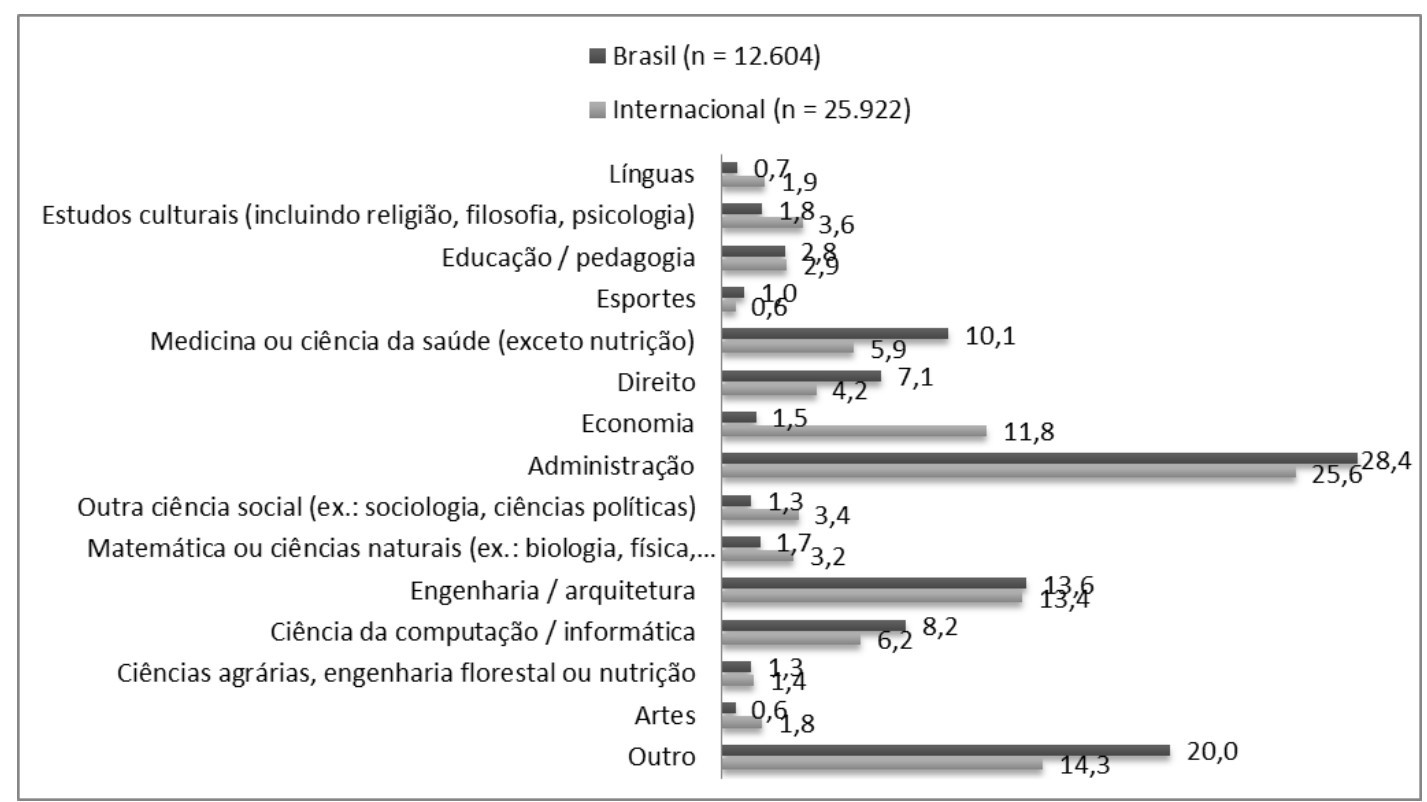

Figura 1. Distribuição dos Fundadores Intencionais por Campo de Estudo (\%)

A categoria outro na Figura 1 refere-se aos estudantes que, ao responderem o questionário, não definiram seu campo de estudo com alguma das opções precisas listadas na Figura 1. 


\section{Resultados}

As hipóteses 1 e 2 não puderam ser confirmadas. Estatisticamente, não há relação entre as variáveis em questão $(p>0,05)$. Em outras palavras, não se pode dizer que haja variação da intenção empreendedora ou do nível de crença de ser competente para empreender com sucesso (autoeficácia em empreendedorismo) dos estudantes que possa ser associada à variação do quanto fazem de disciplinas e atividades de EE.

Esses resultados se somam àqueles de outros estudos que colocam em questão a ideia predominante de que a EE tem sempre uma relação estatisticamente significante e positiva com a autoeficácia e a intenção de empreender. Souitaris, Zerbinati e Al-Laham (2007), por exemplo, concluíram pela indiferença desses constructos em relação a variações da EE. Uma possibilidade explicativa a considerar é que o nível normalmente já elevado de intenção empreendedora e de autoeficácia (segundo a literatura) dos fundadores intencionais faz com que a possibilidade de mudança marginal do nível desses constructos tenda a zero com variações da quantidade de EE. Uma investigação detalhada dessa possibilidade em estudos futuros parece promissora quanto à geração de novos conhecimentos sobre a EE.

Por outro lado, a hipótese 3 foi confirmada. Portanto, há uma relação significante positiva entre a intenção empreendedora e a demanda por EE dos fundadores intencionais estudados. Ou seja, os alunos fundadores intencionais com mais intenção empreendedora têm mais demanda por disciplinas e atividades de EE. No entanto, como já destacado, fazer mais disciplinas e atividades de EE não tem incrementado sua intenção empreendedora e não os faz se perceberem como mais competentes para empreender.

Com base nesses resultados, não se pode dizer que as IES brasileiras completam o ciclo de fortalecimento da díade intenção-potencial para empreender. Em consonância com a descrição da díade feita na introdução, uma maior intenção empreendedora está ocorrendo em concomitância com uma maior demanda por preparação. Mas, quando os estudantes aproveitam a oferta de EE, não percebem que recebem os benefícios esperados dela.

Os respondentes foram convidados a manifestar seu nível de interesse em fazer disciplinas e atividades que informaram não ter feito ou não saber se eram oferecidas em sua IES. As respostas podem ser consideradas uma explicitação de demanda, cujos porcentuais seguem na Tabela 1.

Tabela 1

Demanda por Disciplinas e Atividades*

\begin{tabular}{llcccc}
\hline Tipo de oferta & Item & \multicolumn{3}{c}{ Brasil } & \multicolumn{3}{c}{ Internacional } \\
\cline { 3 - 6 } & & $\begin{array}{c}\text { Gostaria de } \\
\text { fazer (\%) }\end{array}$ & $\begin{array}{c}\text { Não preciso } \\
\mathbf{( \% )}\end{array}$ & $\begin{array}{c}\text { Gostaria de } \\
\text { fazer (\%) }\end{array}$ & $\begin{array}{c}\text { Não preciso } \\
(\mathbf{\%})\end{array}$ \\
\hline Disciplinas & Empreendedorismo em geral & $\mathbf{8 1 , 7}$ & 18,3 & 80,1 & 19,9 \\
& Plano de negócios & $\mathbf{8 5 , 9}$ & 18.6 & 78,7 & 21,3 \\
& Marketing empreendedor & $\mathbf{7 0 , 4}$ & 20,6 & 62,2 & 37,8 \\
& Inovação e geração de ideias & $\mathbf{8 7 , 6}$ & 12,4 & 78,7 & 21,3 \\
& Financiamento para a criação & $\mathbf{8 3 , 7}$ & 16,3 & 79,4 & 20,6 \\
& de empresas & & & & \\
& Empreendedorismo social & $\mathbf{7 5 , 8}$ & 24,2 & 50,8 & 41,2 \\
\hline
\end{tabular}


Tabela 1 (continuação)

\begin{tabular}{llcccc}
\hline Tipo de oferta & Item & \multicolumn{2}{c}{ Brasil } & \multicolumn{3}{c}{ Internacional } \\
\cline { 2 - 5 } & & $\begin{array}{c}\text { Gostaria de } \\
\text { fazer (\%) }\end{array}$ & $\begin{array}{c}\text { Não preciso } \\
\mathbf{( \% )}\end{array}$ & $\begin{array}{c}\text { Gostaria de } \\
\text { fazer (\%) }\end{array}$ & $\begin{array}{c}\text { Não preciso } \\
\text { (\%) }\end{array}$ \\
\hline & $\begin{array}{l}\text { Empreendedorismo } \\
\text { tecnológico }\end{array}$ & $\mathbf{7 6 , 2}$ & 23,8 & 54,8 & 45,2 \\
& Empresas familiares & $\mathbf{6 6 , 2}$ & 33,8 & 46,7 & 53,3 \\
\hline Atividades & $\begin{array}{l}\text { Workshops/networking com } \\
\text { empreendedores experientes }\end{array}$ & $\mathbf{8 1 , 6}$ & 18,4 & 81,9 & 18,1 \\
& $\begin{array}{l}\text { Programa de mentoria e } \\
\text { coaching para } \\
\text { empreendedores }\end{array}$ & $\mathbf{7 7 , 5}$ & 22,5 & 77,2 & 22,8 \\
$\begin{array}{l}\text { Concurso ou workshops de } \\
\text { planos de negócios }\end{array}$ & $\mathbf{7 9 , 8}$ & 20,2 & 67,8 & 32,2 \\
$\begin{array}{l}\text { Serviço tira-dúvidas e de } \\
\text { apoio em empreendedorismo }\end{array}$ & $\mathbf{8 5 , 4}$ & 14,6 & 79,4 & 20,6 \\
$\begin{array}{l}\text { Base para contato com } \\
\text { investidores potenciais }\end{array}$ & $\mathbf{8 5 , 4}$ & 14,6 & 79,4 & 20,6 \\
\hline
\end{tabular}

Nota. * As frequências aqui apresentadas têm diferenças estatisticamente significantes entre as duas amostras, segundo o teste $\mathrm{V}$ de Cramér $(\mathrm{V}<0,13 ; \mathrm{p}<0,05)$.

Como mostra a Tabela 1, os estudantes brasileiros caracterizam-se por uma maior diferença entre gostaria de fazer e não preciso do que os estrangeiros. A única exceção ocorre para Workshop/networking com empreendedores experientes. Quanto à disciplina de empresas familiares, no contexto da EE, ela parece reforçar a sinalização já feita pelos estudos do CFA (Andrade et al., 2006; Mello et al., 2011) da necessidade de conteúdo de formação em administração de micro e pequenas empresas.

Com tais resultados, poder-se-ia dizer que as disciplinas e atividades da Tabela 1 são atraentes como foco de um eventual esforço da melhoria da EE. A tabela sugere a existência de demanda para as disciplinas e atividades tanto nas IES brasileiras quanto nas estrangeiras, mas mais elevada no Brasil. Estão marcados em cinza os valores brasileiros da tabela com mais de 3 pontos porcentuais de superioridade frente à amostra internacional. Essa demanda pode eventualmente significar um facilitador da melhoria da EE.

O facilitador tende a se potencializar com a constatação já existente da alta demanda em IES brasileiras pelas mesmas disciplinas e atividades advindas também de estudantes universitários em geral, não apenas dos que são fundadores intencionais (Lima et al., no prelo). Esses autores usaram uma amostra de 25.751 estudantes brasileiros, incluindo também estudantes não interessados em empreender, além daqueles que são donos de um ou mais negócios.

Testes V de Crámer atestam diferença estatística para os dados sobre demanda na comparação entre respondentes brasileiros separados por grupos de gênero (todos os valores de teste abaixo de 0,113 e com $\mathrm{p}<0,05)$. Em comparação aos homens, as mulheres demonstram menor demanda com a resposta gostaria de fazer $(40,84 \%$ em média; $n$ médio $=1.411$ com dp médio $=480,3)$ e menor rejeição com não preciso $(10,78 \%$ em média; $n$ médio $=372 \mathrm{com}$ dp médio $=178,09)$. Só foram convidados a responder gostaria de fazer ou não preciso aqueles que disseram não ter feito as disciplinas e atividades em questão. O resultado obtido nessa consulta é contrário ao de Lima et al. (no prelo), que identificaram maior demanda das mulheres. Ele implica que, na resposta dos fundadores intencionais a uma pergunta anterior do questionário, foi maior a proporção de mulheres que disseram já ter feito disciplinas e atividades de EE. Assim, no comparativo com estudantes homens, mais respondentes brasileiras que querem ter seu próprio negócio já aproveitaram as ofertas de EE. Daí, uma pergunta pode ser feita: 
haveria relevantes diferenças de gênero a se considerar quanto à preparação dos estudantes para empreender? Caso afirmativo, como isso deveria ser levado em conta para o aperfeiçoamento da EE? Essas poderiam ser questões promissoras para estudos futuros.

Um comparativo adicional com o estudo de Lima et al. (no prelo) mostra que, com exceção das disciplinas marketing empreendedor e empreendedorismo social, a pesquisa feita apenas com estudantes que são fundadores intencionais mostra porcentuais mais elevados de demanda por EE. Isso sugere que, com exceção dessas duas disciplinas, estudantes que são fundadores intencionais tendem a ter mais demanda por EE do que os estudantes em geral, tomados em conjunto e sem distinção se são ou não fundadores intencionais. Com isso, pode-se também vislumbrar que fundadores intencionais tendem a ter maior demanda por EE do que aqueles que não querem criar seu próprio negócio. Notam-se aqui, portanto, tendências convergentes com a hipótese 3. Contudo, percebe-se aí um resultado dissonante em relação a uma das hipóteses não confirmadas (a que se refere a mais demanda por EE quando há mais intenção empreendedora) do estudo de Lima et al. (no prelo) - isso pode ser tomado como mais uma provocação para a elaboração de estudos futuros.

Quanto às duas disciplinas de exceção, parece tentador buscar uma explicação do fato de terem porcentual de demanda mais baixo na amostra de fundadores intencionais. Todavia, faltam-nos elementos para fazê-lo aqui, por ser o estudo de Lima et al. (no prelo) distinto e considerar outra amostra.

\section{Mais resultados e discussões quanto à intenção empreendedora}

A Figura 2 apresenta os porcentuais de resposta para a questão relativa a quão seriamente os fundadores intencionais pensam em empreender.

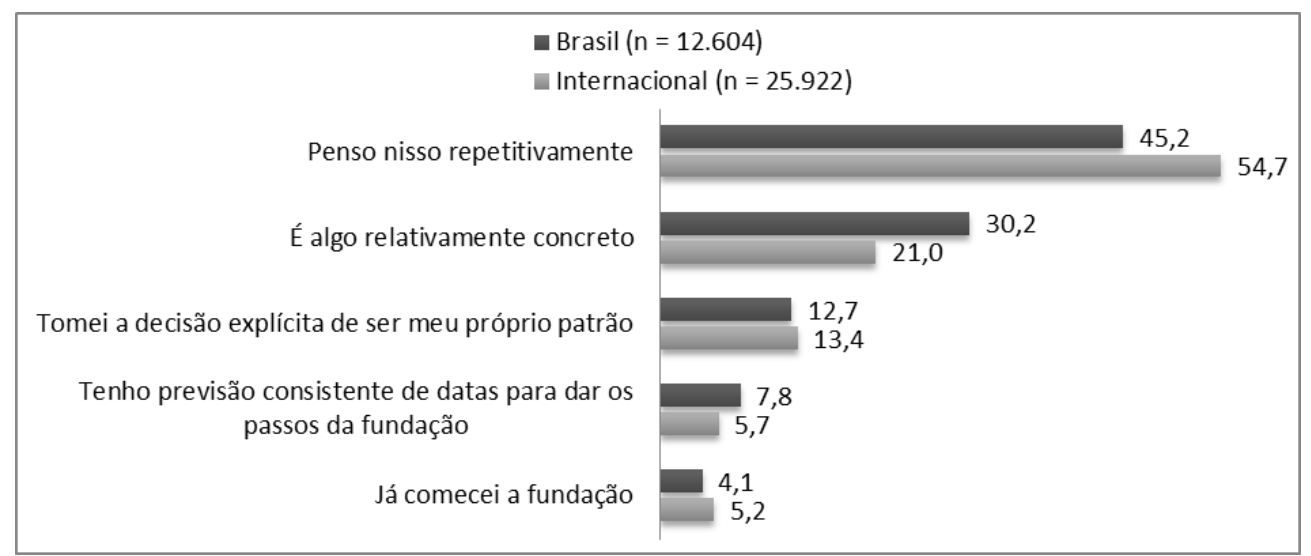

Figura 2. Força da Intenção Empreendedora (\%)*

* As frequências aqui apresentadas têm diferenças significantes entre as duas amostras, segundo o teste $\mathrm{V}$ de Cramér $(\mathrm{V}<0,10$; $\mathrm{p}<0,05)$.

Com a Figura 2, nota-se que é menor o porcentual brasileiro do item penso nisso repetitivamente. A diferença de cerca de 10 pontos porcentuais a menos apresentada pelo Brasil nesse item está distribuída principalmente nos itens é algo relativamente concreto e tenho previsão consistente de datas... Revelam-se assim mais particularidades que destacam a relevância e o caráter promissor do estudo específico da EE voltada aos fundadores intencionais do Brasil.

Uma pequena minoria $(4,1 \%)$ dos respondentes brasileiros já iniciou a fundação de sua empresa. Em outras palavras, poucos deles (mas próximos do porcentual estrangeiro) já têm elevada convicção de se tornar seu próprio patrão e alta estabilidade da ideia de negócio a criar. Estão comprometidos com um curso de ação que eliminou outras iniciativas possíveis para a fundação e que impõe um rol mais restrito de passos viáveis para continuidade desta (path dependence). Estudantes que pensam repetitivamente em criar sua própria empresa são a maioria $(45,2 \%)$, tendendo a ser o grupo com menor convicção para fazê-lo e menor estabilidade e detalhamento da ideia de empreender. É o grupo mais distante da possibilidade de ter alguma path dependence. 
Nesse sentido, a Figura 2 representa a realidade de fundadores intencionais em diferentes níveis de intenção empreendedora e do avanço da decisão quanto a empreender. Esse é frequentemente negligenciado, dado que os estudos normalmente focam o processo empreendedor a partir da decisão já tomada, o que limita o conhecimento da EE mais adequada para os diferentes estágios da decisão de empreender (Liñán, 2007).

Além do que se vê na Figura 2, os dados mostram que 21,8\% dos respondentes brasileiros nada fizeram ainda para fundar seu negócio, e $65,5 \%$ pensaram nas primeiras ideias dele. Na amostra internacional, as porcentagens em questão são $29,1 \%$ e $64,9 \%$ respectivamente. Isso implica que uma proporção maior dos brasileiros informou já ter feito algo para empreender e a maioria deles, assim como dos estrangeiros respondentes, pensou nas primeiras ideias.

A Figura 3 complementa esses números descrevendo apenas as respostas dos que já foram além de pensar nas primeiras ideias. Note-se que, no questionário, os respondentes puderam marcar simultaneamente essas duas respostas precedentes $(21,8 \%$ e $65,5 \%$ para o Brasil) e as demais da Figura 3.

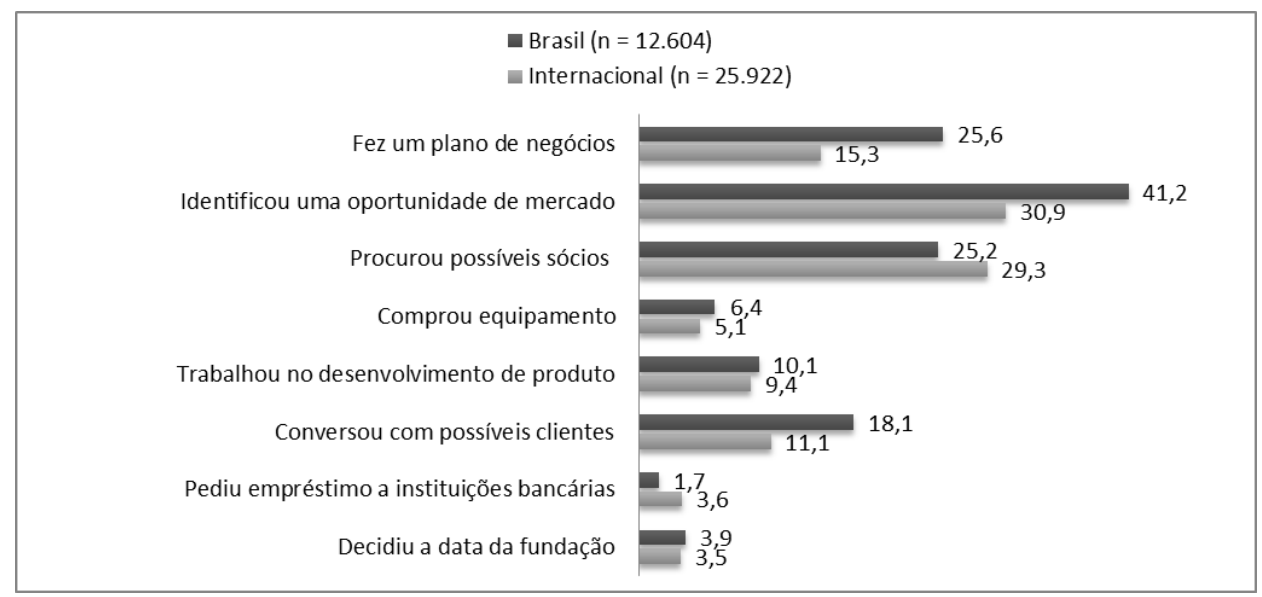

Figura 3. Avanço Feito para Ser seu Próprio Patrão (\%)*

* As frequências aqui apresentadas têm diferenças significantes entre as duas amostras, segundo o teste $\mathrm{V}$ de Cramér $(\mathrm{V}<0,10$; $\mathrm{p}<0,05)$.

Na Figura 3, a maior proporção dos respondentes das duas amostras optou pela resposta identificou uma oportunidade de mercado, principalmente para o Brasil $(41,2 \%)$. Há superioridade do porcentual brasileiro quanto a ter feito um plano de negócios $(25,6 \%)$, resultado que pode estar contando com o foco da EE universitária do Brasil essencialmente nesse instrumento de preparação (Degen, 2009; Guerra \& Grazziotin, 2010).

Considerando-se o processo de decisão para empreender e suas características aqui descritas, os fundadores intencionais seriam beneficiados para realizar sua intenção empreendedora com o foco da EE principalmente em criação de empresas (Liñán, 2007). Com esse foco, receberiam ênfase aspectos como: o desenvolvimento de conhecimentos e competências quanto à identificação e à exploração de oportunidades, aos detalhes do ambiente em que se quer empreender, e aos procedimentos exatos para se abrir a empresa (Liñán, 2007). Tal abordagem mostrar-se-ia especialmente relevante no contexto brasileiro, em que a burocracia, a imprevisibilidade do contexto, a dificuldade de financiamento e outras barreiras para a criação de novos negócios são particularmente elevadas.

Quando conciliada a tal abordagem, a EE que coloca em valor a construção de um plano de negócios também tende a ser salutar (Carrier, 2005; Liñán, 2007). Todavia, o foco estrito nesse instrumento pode ter um efeito negativo sobre o nível de desejo de empreender (Carrier, 2005). Seria essa uma das explicações possíveis da não confirmação das hipóteses 1 e 2? Esse questionamento se impõe dado que o desejo é um elemento básico da intenção empreendedora e está intimamente ligado à autoeficácia, além de a EE no Brasil ser concentrada no plano de negócio. O questionamento poderia ir ainda mais longe pelos mesmos motivos e porque o plano de negócios não é uma estratégia de ensino 
adequada para estudantes que não pensam em empreender (Liñán, 2007). Seria essa uma das explicações possíveis também para o efeito estatisticamente negativo identificado por Lima et al. (no prelo) da EE brasileira sobre a intenção empreendedora e a autoeficácia de universitários em geral? São mais questões que poderiam animar estudos futuros.

Os avanços para empreender listados na Figura 3 podem ser apoiados por uma EE integrada ao desenvolvimento de competências em administração de micro e pequenas empresas. Se essa já é uma importante carência da educação universitária brasileira em Administração (Andrade et al., 2006; Mello et al., 2011), alguém poderia imaginar que tende a ser ainda mais acentuada nos demais cursos universitários.

Com competências, mesmo que modestas, em planejamento, organização do tempo, negociação, compras, marketing e finanças, poder-se-ia esperar que o estudante que é fundador intencional tivesse mais facilidade para fazer os avanços da Figura 3. No entanto, nem todo estudante é de um curso universitário propício ao desenvolvimento de tais competências - como se espera, por exemplo, do curso de Administração. Por isso, ter ao menos disciplinas básicas de Administração tratando dessas competências em seu próprio curso superior ou ter acesso facilitado a disciplinas de Administração seria algo recomendável aos estudantes dos mais variados campos de estudo, e que são fundadores intencionais.

Quanto aos fundadores intencionais mais avançados no projeto de empreender (e mais ainda para aqueles que se tornarem fundadores ativos) mostra-se particularmente promissora a EE com foco na educação continuada de empreendedores, assim como aquela com foco na promoção do comportamento empreendedor mais aperfeiçoado (Liñán, 2007).

\section{Conclusões}

Com nossos resultados de pesquisa, em especial quanto aos não esperados para as hipóteses $1 \mathrm{e}$ 2, e com a revisão da literatura, percebe-se que as necessidades de melhoria da EE no Brasil estão interligadas, tendo ao centro de suas conexões a necessidade de abordagem prática e de interação com os empreendedores e seu mundo real. Isso converge com recomendações da literatura internacional (McCoshan, 2010; Neck \& Greene, 2011; NIRAS Consultants, FORA, ECON Pöyry, 2008; Surlemont \& Kearney, 2009). O atendimento dessas necessidades, tomadas separadamente ou, mais ainda, tomadas em conjunto, parece ser um projeto laborioso e de longo prazo, mas que conta com a predisposição e a demanda favoráveis dos estudantes quanto a melhorias da EE. Esses dois facilitadores se evidenciam com o fato de a força da intenção de empreender dos fundadores intencionais brasileiros ser elevada na comparação com a amostra internacional e de convergir com sua elevada demanda por uma EE variada.

A melhoria da EE guiada pela busca da alta qualidade, com ênfase na prática e no contato com os empreendedores e seu mundo real, poderia gerar contribuições diretas para a formação de um grande contingente de estudantes, e indiretas para o país, particularmente por meio dos estudantes que são fundadores intencionais, como já sustentou a introdução deste artigo. Estes já estão sensibilizados quanto ao empreendedorismo e têm uma necessidade dirigida de preparação para colocarem em prática sua aspiração quanto a empreender. Além disso, tendem a ser os universitários que mais prontamente darão efeito socioeconômico ao que aprenderem em empreendedorismo, dado que já querem ser seus próprios patrões.

No esforço que se mostra necessário para a melhoria da EE, como dito por Hashimoto (2013) e Lima et al. (no prelo), os centros de empreendedorismo têm papel relevante a desempenhar nas IES. Eles têm por função promover ambientes propícios à aprendizagem e ao desenvolvimento do empreendedorismo, com palestras, workshops, atividades práticas e de redes de relacionamento, dentre outros, em frequente vínculo com (pré)incubadoras. Segundo a argumentação de Krueger e Brazeal (1994), esse tipo de ambiente de estímulo e apoio (normalmente liderado por professores que são 
visionários-realizadores, segundo Lima et al., 2014), é essencial para o florescimento de empreendedores potenciais, que dão potencial empreendedor a um país.

Colaborariam para a melhoria da EE estudos comparativos entre IES brasileiras e destas com instituições estrangeiras para a identificação e a disseminação do uso de melhores práticas, assim como estudos sobre os contextos social, econômico e cultural específicos do empreendedorismo no Brasil, e os requisitos necessários no país para que se empreenda com menos dificuldade e mais sucesso.

Dentre as limitações da pesquisa aqui apresentada, lembramos que a amostra, mesmo sendo de grande dimensão, não é aleatória. Isso inibe a possibilidade de generalização dos resultados obtidos, apesar de estes mostrarem grande convergência com resultados de outros estudos e com os do estudo GUESSS internacional. Outra limitação é a possível falta de clareza quanto aos conceitos de empreender, empreendedorismo, ter seu próprio negócio e ser seu próprio patrão entre os respondentes, principalmente entre aqueles de áreas distintas da Administração. Pode contribuir para a limitação a polissemia dos conceitos segundo o que se vê em sua divulgação nos meios de comunicação, por exemplo. Para enfrentar essa dificuldade potencial, utilizamos no questionário uma explicação curta do que é ser seu próprio patrão, visando especialmente aos respondentes de outras áreas que não Administração - como Engenharia, Odontologia, Medicina, Nutrição, Matemática e Física. Ainda assim, não pudemos tirar uma conclusão precisa sobre a eficácia do procedimento, apesar de acreditarmos que foi útil.

Por fim, alguns leitores poderiam questionar o real valor de se utilizar a perspectiva dos estudantes, que não são especialistas em educação, para se identificar formas de se melhorar a educação superior em empreendedorismo. Nesse aspecto, é relevante mencionar que a avaliação e a percepção dos estudantes já têm sido reconhecidas como uma perspectiva a considerar na busca de aperfeiçoamento da educação, principalmente como fizemos em nossa pesquisa, ou seja, em complementaridade com contribuições de especialistas e professores (Ackerman, Gross, \& Vigneron, 2009; Lam, 2006) disponíveis na literatura.

\section{Notas}

1 Uma lista mais completa de trabalhos baseados no GUESSS está disponível em http://guesssurvey.org/e_publication_further.html.

${ }^{2}$ IES brasileiras que participaram do estudo: Centro de Ensino Unificado de Teresina (CEUT), Laureate International Universities (ESADE), Escola Superior de Propaganda e Marketing (ESPM), Faculdade Dom Pedro II, Faculdade Campo Limpo Paulista (FACCAMP), Fac. de Ciências Sociais Aplicadas do Sul de Minas (Facesm), FAE - Centro Universitário, Faculdade de Tecnologia de Pindamonhangaba (Fatec), Faculdade de Tecnologia de São Sebastião (Fatec), Fundação Getúlio Vargas (FGV-SP), Faculdade R Sá, Universidade Regional de Blumenau (FURB), Grupo Uniasselvi, Instituto Federal de Educação (IFPI-Picos), Ciência e Tecnologia do Piauí, Inst. Federal de Educação (IFSP), Ciência e Tecnologia em Caraguatatuba, Insper - Instituto de Ensino e Pesquisa, Universidade do Estado de Santa Catarina (UDESC), Universidade Estadual de Londrina (UEL), Universidade Federal da Bahia (UFBA), Universidade Federal da Grande Dourados (UFGD), Universidade Federal de Itajubá (Unifei), Universidade Federal do Maranhão (UFMA), Universidade Federal do Mato Grosso do Sul (UFMS), Universidade Federal do Mato Grosso (UFMT), Universidade Federal do Paraná (UFPR), Universidade Federal de Sergipe (UFS), Universidade Federal de Santa Catarina (UFSC), Universidade Federal de São João Del-Rei (UFSJ), Universidade Federal de Viçosa (UFV), Universidade Salvador (UNIFACS), União Metropolitana de Educação e Cultura (UNIME), Universidade Nove de Julho (UNINOVE), Universidade do Vale do Sapucaí (Univás), Univates, Universidade Presbiteriana Mackenzie, Universidade São Francisco, Universidade de São Paulo (USP).

${ }^{3}$ Testes estatísticos (test $\mathrm{U}$, test $t$ e/ou teste $\mathrm{V}$ de Cramér) não foram realizados deste ponto até o fim da seção, pois a apresentação de frequências aqui é para fins descritivos, não comparativos. 


\section{Referências}

Ackerman, D., Gross, B. L., \& Vigneron, F. (2009). Peer observation reports and student evaluations of teaching: who are the experts? The Alberta Journal of Educational Research, 55(1), 18-39.

Ajzen, I. (1991). Organization behavioral and human decision process. Chicago: Dorsey Press.

Ajzen, I. (2002). Perceived behavioral control, self-efficacy, locus of control, and the theory of planned behavior. Journal of Applied Social Psychology, 32(4), 665-683. doi: 10.1111/j.15591816.2002.tb00236.x

Alvarez, S. A., \& Busenitz, L. W. (2001). The entrepreneurship of resource-based theory. Journal of Management, 27(6), 755-775. doi: 10.1177/014920630102700609

Andrade, R. O. B., Abreu, J. A. R., Scaico, O., Fortuna, A. A. M., Freitas, A. A., Jr., \& Ferraz, S. F. (2006). Pesquisa nacional sobre o perfil, formação, atuação e oportunidades de trabalho do administrador. Brasília: CFA. Recuperado de http://www.crarn.org.br/novo/arquivos/pesquisa2006\%20internet.pdf

Anjos, G. C. B., Fechine, G. F., \& Nóbrega, A. L. (2005, agosto). Percepção empreendedora dos estudantes de graduação: um estudo de caso no curso de administração da UFCG (Universidade Federal de Campina Grande). Anais dos Seminários em Administração - FEA-USP, São Paulo, SP, Brasil, 8.

Babbie, E. (1990). Survey research methods. Bervely: Wadsworth Publishing.

Bandura, A. (1997). Self-efficacy: the exercise of control. New York: Freeman.

Bergmann, H. (2012, agosto). Opportunity-recognition beliefs among student entrepreneurs - spotting a business opportunity from the ivory tower. Proceeding of the Annual Meeting of the Academy of Management. Boston, MA, 72.

Byrne, J., Fayolle, A., \& Toutain, O. (2014). Entrepreneurship education: what we know and what we need to know. In E. Chell \& M. Karataş-Özkan (Eds.), Handbook of research on small business and entrepreneurship (pp. 261-288). Cheltenham: Edward Elgar.

Brockhaus, R. H. (1980). Risk taking propensity of entrepreneurs. Academy of Management Journal, 23(3), 509-520. doi: 10.2307/255515

Carrier, C. (2005). Pedagogical challenges in entrepreneurship education. In P. Kyrö \& C. Carrier (Eds.), The dynamics of learning entrepreneurship in a cross-cultural university context (pp. 136-158). Hämeenlinna: University of Tampere.

Carter, N. M., Gartner, W. B., Shaver, K. G., \& Gatewood, E. J. (2003). The career reasons of nascent entrepreneurs. Journal of Business Venturing, 18(1), 13-39. doi: 10.1016/S0883-9026(02)00078-2

Chen, C. C., Greene, P. G., \& Crick, A. (1998). Does entrepreneurial self-efficacy distinguish entrepreneurs from managers? Journal of Business Venturing, 13(4), 295-316. doi: 10.1016/S0883-9026(97)00029-3

Degen, R. J. (2009). Empreendedor. São Paulo: Pearson.

Drost, E. A. (2010). Entrepreneurial intentions of business students in Finland: implications for education. Advances in Management, 3(7), 28-35.

Everitt, B. S. (2006). The Cambridge dictionary of statistics (3th ed.). Cambridge: Cambridge University Press. 
Fayolle, A., Gailly, B., \& Lassas-Clerc, N. (2006). Effect and counter-effect of entrepreneurship education and social context on student's intentions. Estudios de Economia Aplicada, 24(2), 509523.

Fishbein, M., \& Ajzen, I. (1975). Belief, attitude, intention, and behavior. An introduction to theory and research. New York: Addison-Wesley.

Franke, N., \& Luthje, C. (2004). Entrepreneurial intentions of business students: a benchmark study. International Journal of Innovation and Technology Management, 1(3), 269-288. doi: 10.1142/S0219877004000209

Galloway, L., Anderson, M., Brown, W., \& Wilson, L. (2005). Enterprise skills for economy. Education and Training, 47(1), 7-17. doi: 10.1108/00400910510580593

Gasse, Y., \& Tremblay, M. (2011). Entrepreneurial beliefs and intentions: a cross-cultural study of university students in seven countries. International Journal of Business, 16(4), 303-314.

Gasse, Y., Camion, C., Ghamgui, A., \& Tremblay, M. (2006). Entrepreneurial intentions: a crosscultural study on university students in three countries [Document de travail $\mathrm{n}^{\circ}$ 2006-019]. Faculté des Sciences de l'Administration, Université Laval, Québec, Canada. Recuperado de http://www.fsa.ulaval.ca/sirul/2006-019.pdf

Gibb, A. (2009). Towards the entrepreneurial university [Working paper]. The National Council for Graduate Entrepreneurship. Retrieved from http://ncee.org.uk/wpcontent/uploads/2014/06/towards_the_entrepreneurial_university.pdf

Greco, S. M. S. S., Bastos, P. A., Jr., Machado, J. P., Felix, J. C., Silvestre, R. G. M., Passos, C. A. K., Schlemm, M., Meza, M. L. F. G., Rissete, C. R., Cunha, S. K., Bulgacov, Y. L. M., Camargo, D., \& Réa, M. X. (2009). Empreendedorismo no Brasil: 2008 (GEM 2008). IBQP: Curitiba. Recuperado de http://201.2.114.249/Sebrae/Portal\%20Sebrae/Anexos/GEM-Brasil-2008.pdf

Guerra, M. J., \& Grazziotin, Z. J. (2010). Educação empreendedora nas universidades brasileiras. In R. M. A. Lopes (Org.), Educação empreendedora: conceitos, modelos e práticas (pp. 67-91). Rio de Janeiro: Elsevier.

Hashimoto, M. (2013). Centro de empreendedorismo no Brasil. São Paulo: Sebrae-SP. Recuperado de http://www.sebraesp.com.br/arquivos_site/biblioteca/guias_cartilhas/ebook_centro_empreended orismo

Hair, J. F., Anderson, R. E., Tatham, R. L., \& Black, W. C. (2010). Multivariate data analisys (7th ed.). New Jersey: Prentice Hall.

Heinonen, J., Kovalainen, A., \& Pukkinen, T. (2006). Global entrepreneurship monitor, executive report Finland (Report series B2/2006), Turku, Finland, Turku School of Economics and Business Administration.

Kirby, D. A. (2005). A case for teaching entrepreneurship in higher education. Retrieved from http://www.heacademy.ac.uk/employability/EMP035_AcaseforTeachmgEntrepreneurship.rtf

Kourilsky M. L., \& Walstad, W. B. (1998). Entrepreneurship and female youth: knowledge, attitudes, gender differences and educational practices. Journal of Business Venturing, 13(1), 77-88. doi: $10.1016 / \mathrm{S} 0883-9026(97) 00032-3$

Krueger, N. F., \& Brazeal, D. V. (1994). Entrepreneurial potential and potential entrepreneurs. Entrepreneurship: Theory and Practice, 18(2), 91-104.

Lam, T. C. (2006). Group problem-solving among teachers: a case study of how to improve a colleague's teaching. Social Psychology of Education, 9(3), 273-299. doi: 10.1007/s11218-006-0005-5 
Lanero, A., Vázquez, J. L., Gutiérrez, P., \& García, M. P. (2011). The impact of entrepreneurship education in European universities: an intention-based approach analyzed in the Spanish area. International Review on Public and Non-Profit Marketing, 8(2), 111-130. doi: 10.1007/s12208011-0067-8

Laspita, S., Breugst, N., Heblich, S., \& Patzelt, H. (2012). Intergenerational transmission of entrepreneurial intentions. Journal of Business Venturing, 27(4), 414-435. doi: 10.1016/j.jbusvent.2011.11.006

Levenson, H. (1973). Multidimensional locus of control in psychiatric patients. Journal of Consulting and Clinical Psychology, 41(3), 397-404. doi: 10.1037/h0035357

Levy, P. S., \& Lemesshow, S. (1999). Sampling of populations: methods and applications. New York: John Wiley \& Sons.

Lima, E., Hashimoto, M., Melhado, J., \& Rocha, R. (2014). Brasil: em busca de uma educação superior em empreendedorismo de qualidade. In F. P. Gimenez, E. C. Camargo, A. D. L. Moraes, \& F. Klosowski (Orgs.), Educação para o empreendedorismo (pp. 128-149). Curitiba: UFPR.

Lima, E., Lopes, R. M., Nassif, V., \& Silva, D. da (no prelo). Opportunities to improve entrepreneurship education: contributions considering Brazilian challenges. Journal of Small Business $\begin{array}{llll}\text { Management. } & \text { doi: } & 10.1111 / \mathrm{jsbm} .12110 . & \text { Retrieved from }\end{array}$ http://onlinelibrary.wiley.com/doi/10.1111/jsbm.12110/abstract

Liñán, F. (2007). The role of entrepreneurship education in the entrepreneurial process. In A. Fayolle (Ed.), Handbook of research in entrepreneurship education - a general perspective (Vol. 1, pp. 230-247). Cheltenham, Northampton: Edward Elgar.

Liñán, F., \& Chen, Y. W. (2009). Development and cross-cultural application of a specific instrument to measure entrepreneurial intentions. Entrepreneurship: Theory and Practice, 33(3), 593-617. doi: 10.1111/j.1540-6520.2009.00318.x

McCoshan, A. (2010). Towards greater cooperation and coherence in entrepreneurship education (Report), Birmingham, UK, European Commission, Directorate-General for Enterprise and Industry. Retrieved from http://ec.europa.eu/enterprise/policies/sme/promotingentrepreneurship/education-training-entrepreneurship/reflectionpanels/files/entr_education_panel_en.pdf

Mello, S. L. de, Melo, J. S. M., Jr., \& Mattar, F. N. (2011). Perfil, formação, atuação e oportunidades de trabalho do administrador: pesquisa nacional (5a ed.). Brasília: CFA. Recuperado de http://www.cfa.org.br/acoes-cfa/pesquisa-nacional/PesquisaPerfil20111.pdf

Miller, B., Bell, J., Palmer, M., Gonzalez, A., \& Petroleum, P. (2009). Predictors of entrepreneurial intentions: a quasi-Experiment comparing students enrolled in introductory management and entrepreneurship classes. Journal of Business \& Entrepreneurship, 21(2), 39-62.

Neck, H. M., \& Greene, P. G. (2011). Entrepreneurship education: known worlds and new frontiers. Journal of Small Business Management, 49(1), 55-70. doi: 10.1111/j.1540-627X.2010.00314.x

Nelson, R., Lima, E., \& Nassif, V. (2014). Family social class effects on entrepreneurship [Working Paper n. 2014-01]. Universidade Nove de Julho, São Paulo, SP, Brasil. Recuperado de https://grupoapoe.files.wordpress.com/2014/08/wp-2014-01-social-class-entrepreneurshipgrupo-apoe.pdf

NIRAS Consultants, FORA, ECON Pöyry. (2008). Survey of entrepreneurship in higher education in Europe (Main Report). $\quad$ Retrieved from http://ec.europa.eu/enterprise/policies/sme/files/support_measures/training_education/highedsur vey_en.pdf 
Peterman, N. E., \& Kennedy, J. (2003). Enterprise education: influencing students' perceptions of entrepreneurship. Entrepreneurship: Theory and Practice, 28(2), 129-144. doi: 10.1046/j.15406520.2003.00035.x

Pihie, Z. A. L. (2009). Entrepreneurship as a career choice: an analysis of entrepreneurial self-efficacy and intention of university students. European Journal of Social Sciences, 9(2), 338-349.

Reynolds, P. D. (1991). Sociology and entrepreneurship: concepts and contributions. Entrepreneurship: Theory and Practice, 16(2), 47-70.

Shapero, A. (1981). Self-renewing economies. Economic Development Commentary, 5(4), 19-22.

Shapero, A., \& Sokol, L. (1982). The social dimension of entrepreneurship. In C. A. Kent, D. L. Sexton, \& K. H. Vesper (Eds.), The encyclopedia of entrepreneurship (pp. 72-90). Englewood Cliffs: Prentice Hall.

Sieger, P., Fueglistaller, U., \& Zellweger, T. (2011). Entrepreneurial intentions and activities of students across the world (International Report of the GUESSS Project 2011), St. Gallen, University of St. Gallen. Retrieved from http://www.guesssurvey.org/PDF/2011/GUESSS_INT_2011_FINAL.pdf

Souitaris, V., Zerbinati, S., \& Al-Laham, A. (2007). Do entrepreneurship programs raise entrepreneurial intention of science and engineering students? The effect of learning, inspiration and resources. Journal of Business Venturing, 22(4), 566-591. doi: 10.1016/j.jbusvent.2006.05.002

Suedekum, G., \& Miller, A. (2011). Empreendedorismo nas universidades brasileiras. São Paulo: Endeavor. Recuperado https://docs.google.com/file/d/0B6ZW664B0pZWdGIwNE9UVWJRZFNWaUVZUllrcmY5dw/ edit?pli=1

Surlemont, B., \& Kearney, P. (2009). Pédagogie et esprit d'entreprendre. Brussels: De Boeck.

Tran, V.-T. (2011, August). La perception de la carrière entrepreneuriale des étudiants vietnamiens. Proceeding of the Conference on Contributions of Social Sciences - Humanity in Economic and Social Development. Hanói, Vietnan. Recuperado de http://tainguyenso.vnu.edu.vn/jspui/bitstream/123456789/3954/1/Tran\%20Van\%20Trang_LA\% 20PERCEPTION\%20DE\%20LA\%20CARRIERE\%20ENTREPRENEURIALE\%20DES\%20E TUDIANTS\%20VIETNAMIENS.pdf

United Nations Conference on Trade and Development. (2011). Entrepreneurship education, innovation and capacity-building in developing countries. Geneva: Author. Recuperado de http://unctad.org/en/Docs/ciimem1d9_en.pdf

Vyakarnam, S. (2005). Embedding entrepreneurship education at the university level [Working Paper]. Retrieved from https://www.researchgate.net/publication/267792310_Embedding_entrepreneurship_education_ at_the_University_level

Wilson, F., Kickul, J., \& Marlino, D. (2007). Gender, entrepreneurial self-efficacy, and entrepreneurial career intentions: implications for entrepreneurship education. Entrepreneurship: Theory and Practice, 31(3), 387-406. doi: 10.1111/j.1540-6520.2007.00179.x

Zellweger, T., Sieger, P., \& Halter, F. (2011). Should I stay or should I go? Career choice intentions of students with family business background. Journal of Business Venturing, 26(5), 521-536. doi: 10.1016/j.jbusvent.2010.04.001 


\section{Dados dos Autores}

\section{Edmilson Lima}

Av. Francisco Matarazzo, 612, Água Branca, 05001-100, São Paulo, SP. Brasil. E-mail: edmilsonolima@gmail.com

Rose Mary Almeida Lopes

Rua Dr. Álvaro Alvim, 123, Vila Mariana, 04018-010, São Paulo, SP, Brasil. E-mail: roselopesbr@uol.com.br

Vânia Maria Jorge Nassif

Av. Francisco Matarazzo, 612, Água Branca, 05001-100, São Paulo, SP. Brasil. E-mail: vania.nassif@uol.com.br

Dirceu Silva

Av. Francisco Matarazzo, 612, Água Branca, 05001-100, São Paulo, SP. Brasil. E-mail: dirceuds@ gmail.com 